University of Nebraska - Lincoln

DigitalCommons@University of Nebraska - Lincoln

Educational Psychology Papers and

Publications

Educational Psychology, Department of

May 2004

\title{
Home-school Collaboration and Bullying: An Ecological Approach to Increase Social Competence in Children and Youth
}

\author{
Susan M. Sheridan \\ University of Nebraska-Lincoln, ssheridan2@unl.edu \\ Emily D. Warnes \\ University of Nebraska-Lincoln, ewarnes2@unl.edu \\ Shannon Dowd \\ University of Nebraska-Lincoln
}

Follow this and additional works at: https://digitalcommons.unl.edu/edpsychpapers

Part of the Educational Psychology Commons

Sheridan, Susan M.; Warnes, Emily D.; and Dowd, Shannon, "Home-school Collaboration and Bullying: An Ecological Approach to Increase Social Competence in Children and Youth" (2004). Educational Psychology Papers and Publications. 11.

https://digitalcommons.unl.edu/edpsychpapers/11

This Article is brought to you for free and open access by the Educational Psychology, Department of at DigitalCommons@University of Nebraska - Lincoln. It has been accepted for inclusion in Educational Psychology Papers and Publications by an authorized administrator of DigitalCommons@University of Nebraska - Lincoln. 
Published in:

\section{Bullying in American Schools: A Social-Ecological Perspective on Prevention and Intervention}

Edited by Dorothy L. Espelage (University of Illinois, Urbana-Champaign) and Susan M. Swearer (University of Nebraska-Lincoln)

Published by Lawrence Erlbaum Associates, Mahwah, New Jersey \& London, 2004.

Copyright (c) 2004 Lawrence Erlbaum Associates.

Used by permission. 


\title{
13
}

\section{Home-school Collaboration and Bullying: An Ecological Approach to Increase Social Competence in Children and Youth}

\author{
Susan M. Sheridan, Emily D. Warnes, \\ and Shannon Dowd \\ University of Nebraska-Lincoln
}

Bullying and other forms of violence among children and youth is a prevalent concern among educators, psychologists, and families alike. Families and schools represent the primary systems in children's lives, and schools and homes are their primary learning contexts. These ecological contexts provide important frameworks within which development occurs. Healthy development occurs most seamlessly when there are congruent and consistent messages delivered across contexts, and healthy and constructive relationships among them. The development of meaningful partnerships among these systems on behalf of children and youth is particularly important to produce positive, lasting outcomes. Thus, an optimal focus for interventions aimed at bullying and victimization exists in the cross-setting contexts of home and school.

This chapter will focus on consultation processes for working across home and school ecologies to address concerns related to bullying and social competence. Included is information on (a) consultation strategies aimed at developing partnerships among parents and educational professionals to help develop social competence in children (i.e., bullies, victims, bystanders); (b) procedures for assessing the child and environment to identify sources of difficulties as well as facilitators to support social skillfulness; and (c) strategies for implementing interventions across home and school settings to enhance social competence. 


\section{ECOLOGICAL SYSTEMS THEORY}

According to ecological-systems theory (Bronfenbrenner, 1979), and as articulated in an earlier chapter (Swearer \& Espelage, Chapter 1), a child is an inseparable part of a small social network comprised of multiple interrelated systems. The microsystem describes the relation of the child with an immediate ecosystem and setting (e.g., home or school). The mesosystem describes interrelations among major ecosystems in the child's life (e.g., home and school), and focuses on the interface of contexts for children's behaviors and performance. The exosystem and macrosystem represent influences from broader and more diffuse contexts including settings in which a child does not directly participate, and overall cultural or subcultural patterns, respectively.

In their Contextual-Systems Model, Pianta and Walsh (1996) denote a clear understanding of systems influences and children at risk. These authors extend the discussion of risk variables beyond status characteristics inherent to the child or family (e.g., poverty). They articulate the importance of the quality of familyschool relationships, or lack thereof, as a primary contributing factor to level of child risk. Thus, children can be considered at greater risk of developing unhealthy or nonproductive patterns of behaviors if the major support systems in their lives (family members, school personnel, community contexts) are operating at odds with each other. That is, high-risk circumstances occur when children derive meanings from home or school that result in conflicting emotions, motivations or goals. Alternatively, children develop in low-risk circumstances if the child/family and school systems communicate, and provide children with congruent messages about expectations and standards for behavior. A major premise of this chapter is that relationships among the systems are central in addressing issues faced by children at risk for serious social or emotional problems, or who demonstrate serious behavioral problems (such as aggression, violence, or gangrelated episodes).

\section{Research Support for Home-School Partnerships}

In recent decades, numerous studies have demonstrated unequivocally that the establishment of productive, constructive, collaborative relationships between parents and teachers is essential for maximizing a student's potential. Parent involvement in their children's educational experiences is positively associated with benefits for students. When parents are involved, students show improvement in academic domains such as grades (Fehrmann, Keith, \& Reimers, 1987), reading test scores (Clark, 1988; Comer, 1988; Epstein, 1991; Stevenson \& Baker, 1987), math achievement (Epstein, 1986), attitude toward schoolwork (Kellaghan, Sloane, Alvarez, \& Bloom, 1993), completion of homework (Clark, 1993; Epstein \& Becker, 1982), academic perseverance (Estrada, Arsenio, 
Hess, \& Holloway, 1987), and participation in classroom learning activities (Collins, Moles, \& Cross, 1982; Sattes, 1985). Also improved are behaviors (Comer \& Haynes, 1991; Steinberg, Mounts, Lamborn, \& Dornbusch, 1991) and self-esteem (Collins et al., 1982; Sattes, 1985). Additionally, benefits for students include fewer placements in special education (Lazar \& Darlington, 1978), greater enrollment in post secondary education (Baker \& Stevenson, 1986; Eagle, 1989; Marjoribanks, 1988), higher attendance rates (Collins et al., 1982), lower dropout rates (Rumberger, 1995), fewer suspensions (Comer \& Haynes, 1991), and realization of exceptional talents (Bloom, 1985). Furthermore, findings from the National Longitudinal Study on Adolescent Health revealed that adolescents have a higher probability of avoiding high-risk behavior (e.g., substance abuse, violence) when they feel connected to their families and their parents are involved in their lives (Resnick et al., 1997).

Parent participation in education also benefits teachers and parents. When parents are actively involved, they report enhanced interpersonal and teaching skills among their child's teachers. Likewise, parent participation has been associated with higher ratings of teaching performance by principals, and greater job satisfaction of teachers (Christenson, 1995). Parent benefits include an increased sense of self-efficacy regarding parenting practices (Davies, 1993; Kagan \& Schraft, 1982), increased understanding of programs for their child (Epstein, 1986), greater appreciation for the role they play in their children's education (Davies, 1993), improved communication with their children (Becher, 1984), and greater involvement in home learning activities (Epstein, 1995). In sum, the more clearly and explicitly parents and educators communicate and collaborate in their work with children, the greater the probabilities for success of interventions (Conoley, 1987; Hansen, 1986). One model by which parents and service providers can communicate and collaborate on behalf of children at risk is conjoint behavioral consultation (CBC; Sheridan, Kratochwill, \& Bergan, 1996).

\section{CONJOINT BEHAVIORAL CONSULTATION}

Conjoint behavioral consultation (CBC) is a structured indirect model of service delivery designed to bring parents and teachers together to address the academic, social, and behavioral needs of a student for whom all parties bear some responsibility (Sheridan et al., 1996). CBC is embedded within an ecological systems framework, which emphasizes (a) reciprocal interactions between the child and the primary systems in his/her life, and (b) collaborative problem solving and decision making across those systems. Participants are parents, teachers, and other caregivers, with structure and guidance provided by a consultant (i.e., a specialist such as a school psychologist).

The foundation of $\mathrm{CBC}$ in ecological-systems theory provides several advantages. First, the reciprocal nature of interactions between the child and 
environment, as well as the interrelations among systems allows for an integrated assessment of the factors that influence the child, thereby enhancing diagnosis and treatment (Sheridan et al., 1996). In addition, CBC provides an opportunity for an interactive partnership between home and school systems that emphasizes mutual responsibility and support. Finally, the structured problem solving process encourages the primary caregivers in the child's life to become actively involved in decision-making (Christenson \& Sheridan, 2001).

To facilitate collaborative partnerships, $\mathrm{CBC}$ engages parents and teachers in a joint problem solving process. The structured model consists of four-stages: including problem identification, problem analysis, treatment implementation and treatment evaluation.

\section{Problem Identification}

The first stage of CBC is problem identification (Sheridan et al., 1996). During this stage, parents and teachers work together with a consultant to identify the specific social concerns for which consultation services are sought. Two primary goals are met through problem identification. First, a thorough assessment of the presenting social concerns is conducted. Second, a specific behavior is selected for intervention (e.g., resolving arguments, accepting "no," cooperating with peers). The goals are considered within the context of the broader ecology within which these issues present. That is, identification of a "problem" is always considered in relation to a broad range of ecological conditions. These include intrapersonal (within person), interpersonal (person-person), and contextual (person-setting) conditions. To address each of these objectives, parents and teachers are involved through mutual and collaborative means.

\section{Ecological Assessment of Social Concerns}

In assessing the social concerns of children and youth, the consultation team focuses attention on three distinct areas that effect social functioning. These include (a) child characteristics, (b) contextual variables, and (c) the match or "fit" between the child and his or her context. Each of these areas contributes to children's abilities to function in a socially competent manner within their environment.

Child Characteristics. When assessing social functioning through the consultation process, the behavioral, interpersonal, and cognitive characteristics that contribute to a child's social competence are considered. Assessment of social functioning can be completed using methods such as direct behavioral observations, parent and teacher reports, and child self-reports (Sheridan \& Elliott, 1991; Sheridan \& Walker, 1999).

Direct behavioral observations allow for assessment of behaviors in a social context (Elliott \& Busse, 1991; Hops, Walker, \& Greenwood, 1988; 
Merrell \& Gimpel, 1998; Sheridan \& Elliott, 1991; Sheridan \& Walker, 1999). Direct observations provide opportunities to examine a child in multiple natural settings (e.g., home and school) and assess the frequency with which he/she interacts with peers and the range of appropriate and inappropriate behaviors in his or her repertoire. Specific social behaviors that either impede or facilitate social functioning also can be determined through direct observations. For example, a child may be observed to exhibit numerous aggressive behaviors that decrease the likelihood that peers invite the child to play. Likewise, observations may indicate that a child is particularly outgoing and approaches others without trepidation. Although such disinhibition may be considered a particular strength in some contexts, qualitative aspects of the approach (e.g., running into an existing game or activity, yelling at other children) may be viewed as inappropriate or unacceptable by peers, leading to lack of social acceptance and possible victimization by others. Another child may be observed to be the recipient of taunting and teasing, and his/her responses identified as a target for intervention.

Finally, direct observations in naturalistic settings allow for comparison of social behavior within a peer-based context. Observers can determine the types of behaviors that are considered "typical" or socially acceptable in the peer group and compare the rate or frequency of a child's behaviors to that of the norm group, thus allowing for a focused direction for skill development.

Parent and teacher report is another method of assessing child characteristics that contribute to social functioning (Elliott \& Busse, 1991; Merrell \& Gimpel, 1998; Sheridan \& Elliott, 1991; Sheridan \& Walker, 1999). Rating scales are based on the assumption that parents and teachers are knowledgeable and capable of providing accurate information regarding a child's interaction with peers and others in the social environment. Data from rating scales provide information regarding a target child's social strengths, as well as performance or skill deficit areas. Standardized scales such as the Social Skills Rating System (SSRS; Gresham \& Elliott, 1990) and the Walker-McConnell Scale for Social Competence and School Adjustment (WMS; Walker \& McConnell, 1988) allow for a developmental and norm referenced perspective of a child's social behaviors.

Finally, child self-report is a method of assessing individual variables that contribute to social functioning (Bracken, 1993; Elliott \& Busse, 1991). Although the aforementioned assessment strategies help define the particular behaviors that may be exhibited in social environments, intrapersonal conditions (specific social cognitions such as interpretations, expectations, attributions, selfefficacy) are not accounted for through these methods. Child interviews and selfreports provide information regarding cognitions and perceptions regarding the social environment (Sheridan \& Walker, 1999). The manner in which a child conceptualizes and interprets his/her own social behaviors and those of peers may affect the type of social strategies used to interact with others (Crick \& Dodge, 1994). Different cognitions about social information can lead to a variety of actions and reactions in social situations, encouraging utilization of a range of 
strategies (some effective and some ineffective). Child interviews can be useful to inquire about self-perceptions of social status and peer responses. These reports provide valuable information regarding a child's social cognitions (i.e., the manner in which he/she views the social world) that can be obtained only from a child him or herself.

Ecological/Contextual Variables. Not only do individual variables influence a child's social behavior, but the environmental context greatly affects that child's social functioning. Intervention efforts must rely on a thorough understanding of the complexity of the contextual variables that reinforce and/or inhibit social behavior (Haring, 1992). Thus, it is important that contextual and environmental variables that contribute to social competence be assessed. This can be done through techniques such as ecological observations and structured behavioral interviews with parents and teachers (Sheridan, Hungelmann, \& Maughn, 1999; Sheridan \& Walker, 1999).

Key to understanding social context is a careful analysis of various factors within the environment that support social interactions, including a determination of the types of behaviors that are normative in social contexts (Sheridan et al., 1999). Observations of the ecological context provide an opportunity to monitor qualitative aspects of the behavior of socially competent peers and identify the strategies used by such children to interact effectively with others. As mentioned previously, a target child's behavior can then be compared to that of the norm group, allowing for focused intervention in skill areas where the child is experiencing relative difficulties. Hoier and colleagues (e.g., Hoier \& Cone, 1987; Hoier, McConnell, \& Pallay, 1987) promoted the use of "template matching," wherein behavioral profiles (templates) of socially competent peers are constructed, creating behavioral norms among relevant peer groups. Using this procedure, the behaviors of socially skilled children are thoroughly assessed and incorporated into a template that characterizes social competence. This behavioral template can then be compared to the profiles of a target child to identify areas of social-behavioral strengths and weaknesses. Comparing qualitative aspects of a target child's social behavior to that of competent peers allows for a focus on socially valid and meaningful areas for intervention.

Ecological observations are also helpful in identifying various stimuli in the environment that reinforce or discourage specific social behaviors (Elliott \& Busse, 1991; Sheridan et al., 1999; Sheridan \& Walker, 1999). Consideration of these variables allows for a functional assessment, conducted to understand the purpose of specific behaviors engaged in by a child. Specifically, antecedents, consequences, and situational events surrounding the child's social behavior can be discerned through direct observation. These are often interpersonal (personperson) in nature.

Antecedents are events, actions, or conditions that establish the context for negative behavior to occur. Understanding precipitants to aggression is an 
important aspect of the problem-solving process for two reasons. First, examination of events that precipitate violence will help consultants identify factors that may be under their control (Keller \& Tapasak, 1997). These include antecedents to violence or aggressive acts such as wearing a certain type of clothing or using certain forms of provocative language. Second, the identification of distal antecedents that may occur outside of the primary intervention setting, such as teasing on the bus or lack of supervision at home (Keller \& Tapasak, 1997) may broaden the focus of intervention in a comprehensive approach to the problem.

Consequences are events or responses to actions that reinforce or maintain a behavior. For example, a student who has an expectation of retaliation by another peer for reporting observed aggressive behaviors may lead that child to "stand by" and refrain from assisting another peer who is being teased. Similarly, a child may provide significant attention (positive or negative) for disruptive actions. For some, this may serve to reinforce socially unacceptable behavior if positive attention for pro-social behaviors is not experienced.

Ecological or situational events are person-setting conditions in the environment that encourage or maintain the occurrence of a prosocial or antisocial behavior. For example, the physical make-up of a school building, playground, or lunchroom can be considered ecological conditions. Bullying and aggressive behavior tends to occur in crowded areas such as stairways, cafeterias, and hallways. Other common ecological conditions include bathrooms, locker areas and entrances and exits to the building. Finally, periods of transition have been shown to increase the occurrence of violence in a school building (Goldstein, Harootunian, \& Conoley, 1994).

Like ecological observations, structured behavioral interviews provide a method for gathering information about the functions of a child's social behavior (Elliott \& Busse, 1991; Sheridan \& Elliott, 1991; Sheridan \& Walker, 1999). Interview questions with parents and teachers can be tailored to inquire about the antecedents, consequences, and sequential conditions surrounding a child's behaviors in different social settings (e.g., home and school). The structured interview format used in CBC allows for a thorough examination of these variables (Sheridan et al., 1996). Through the interview process, an identification of the functions or purpose of social behavior is possible. This information then can be used to create meaningful prosocial interventions for the child.

Match or "Fit" Between the Child and Context. Following careful analysis of the individual child and contextual variables that influence social functioning, the "fit" or match between the child's behavior and his or her social environment can be determined. Certain social behaviors may be adaptive and functional in some social settings, but not in others (Haring, 1992; Sheridan et al., 1999). Expectations and normative behaviors vary across contexts; thus, what is appropriate in one setting may not be socially acceptable in another. For example, it may be acceptable for a child to lick his fingers during meals while at 
home; however, this same behavior may not be viewed as socially appropriate in the school cafeteria and lead to taunting and teasing from peers. Likewise, high energy and roughhouse play may be acceptable on the playground, but is clearly not appropriate in the classroom setting during free play opportunities. In addition to the variations in expectations and normative behaviors among social settings, a child's behavior may be reinforced differentially depending on the context. For example, a child may be encouraged by school staff to socialize with his or her peers while at school, although this same child may not be expected to socialize outside of the family system and may have limited opportunities to play with peers when at home. In a similar vein, direct verbal conflict management strategies may be reinforced at school, whereas in a particular family context, aggressive or other physical means for asserting one's rights may be taught. In the context of home-school partnerships, differences among the child's social settings can be explored, and the apparent match or mismatch between the child's behavior and his or her environments can be identified.

\section{Selection of a Target Behavior}

The second goal of the problem identification stage of $\mathrm{CBC}$ includes the selection of a target behavior for intervention (Sheridan et al., 1996). It is important that the target behavior selected in consultation leads to meaningful treatment outcomes. Central to this discussion is the construct of social validity, which is defined as the degree to which therapeutic changes are socially important or meaningful to a client (Kazdin, 1977). Specifically, socially valid target behaviors are those that, when modified, bring about changes that influence a child's ability to function effectively within his or her social network. Analysis of existing social behaviors and the contextual environments allows for identification of appropriate and meaningful areas for intervention. The assessment techniques mentioned above (e.g., child and ecological observations, behavioral interviews, and parent and teacher report) provide for this type of analysis.

Meaningful targets for intervention are those that will be naturally reinforced in the social environment, such that the behavior or skill that is learned will be maintained over time in the absence of formal intervention. For example, teaching a child to organize play activities, give genuine compliments, or problem solve will likely lead to a positive response from peers, thus encouraging future instances of similar prosocial behaviors. Template matching (Hoier \& Cone, 1987), as described earlier, yields an objective means for identifying normative expectations that can be naturally reinforcing.

Once a target behavior has been selected, it is important to develop a clear operational definition (Sheridan et al., 1996) that is concrete, observable, specific, and objective. These criteria allow parents, teachers, and the consultant to specify clearly the problem being addressed in consultation, and to collect relevant data throughout the course of consultation. These data are used to monitor treatment 
effects over time and make decisions regarding the goals for consultation and the modification of interventions.

\section{Problem Analysis}

Problem analysis is the second stage in the $\mathrm{CBC}$ process. The primary objectives of this stage are to (a) conduct a functional assessment of the behavior, and (b) develop a cross-setting treatment plan (Sheridan et al., 1996).

\section{Functional Assessment}

Functional assessment is conducted to evaluate the purpose or function of specific behaviors (such as aggression or withdrawal) engaged in by the child. Through structured assessment of the environmental factors surrounding the child's behaviors, it is possible to identify and influence variables that reinforce and thereby maintain the behavior. Although environmental factors are initially assessed through observation during the problem identification stage of consultation, similar conditions are re-assessed in a structured way across home and school settings during the problem analysis stage.

Functional assessments designed to increase social competence should include assessment across all social settings. Social behaviors might be topographically similar (e.g., arguing with peer), yet serve different functions in different contexts (e.g., escape a task or demand in the classroom, receive attention on the playground). Similarly, topographically dissimilar behaviors (e.g., arguing, helping a peer) may serve the same function (e.g., attention) across multiple settings. Therefore, hypotheses regarding the function of social behaviors should be tested via direct manipulation of environmental variables (Sheridan et al., 1999). Making deliberate changes in reinforcement contingencies and environmental structure can help identify variables that impact behavior. Utilizing findings from functional assessment to provide direct linkages between assessment of ecological stimuli and intervention strategies is crucial.

\section{Plan Development}

The second objective of the problem analysis stage in CBC is to develop a cross-setting plan including specification of environmental conditions to be manipulated (Sheridan et al., 1996). An important consideration for this stage is treatment acceptability, or consultees' (parents' and teachers') perceptions regarding social intervention procedures. Interventions that promote a philosophy contrary to parent and teacher belief systems may be viewed as unacceptable and may not implemented, or may be implemented incorrectly. For example, a behavioral strategy such as positive reinforcement may be perceived as "bribery" and thereby implemented sporadically or not at all. Early research on treatment acceptability has suggested that interventions that are seen as high in cost (e.g., in 
terms of time, money, or resources) may be viewed as undesirable, and result in reduced implementation (Witt, Martens, \& Elliott, 1984). Conversely, plans that incorporate positive rather than aversive components may be viewed more favorably. Finally, interventions that target more severe concerns are generally rated as more acceptable (Witt et al., 1984).

Lewis, Sugai and Colvin (1998) designed and implemented a school violence intervention program that was intended to increase acceptability in natural settings. Variables such as teacher time for planning, amount of teacher expertise, and time available for intervention supervision were considered. Based on these considerations, the authors purposefully left some variables uncontrolled to allow for a fit of the intervention within the parameters of daily school operations. There were no systematic efforts to ensure intervention integrity outside of informal staff contacts, and loose criteria to reward students were established (Lewis et al., 1998), yet generally positive results were found.

\section{Strategies for Increasing Social Competence}

In addition to developing a plan that is acceptable to all parties, it is crucial that the intervention has evidence of efficacy for similar target behaviors and situational contexts (Kratochwill \& Stoiber, 2002). The development of effective interventions must consider internal (i.e., child-related) and external (i.e., environmental or contextual) factors. For example, teaching a child discrete steps to use self-control, manage conflicts, or assert oneself is important to ensure he/she has the skills to perform these behaviors. However, social interactions do not occur in isolation. Variables of other peers with whom problem solving will occur will be important to address. These variables may include interaction styles, skills, behaviors and goals of the other students (Sheridan \& Walker, 1999). Several childfocused (within-person) strategies and environmental/contextual (person-person and person-setting) strategies have been developed that successfully increase social competence in children and adolescents. These are reviewed next.

Child-focused Strategies. Child-focused interventions are designed to promote skill acquisition and encompass several strategies including modeling, coaching and social problem-solving (Sheridan \& Walker, 1999). One of the most effective strategies is modeling, or the process by which a new behavior is learned through observing another person engage in that behavior (Gresham, 2002). Modeling can be viewed as a three-step process. The first step, skill instruction, includes a rationale for the behavior and presentation of the sequence of actions involved in the skill. Demonstration of the skill by a trainer, therapist, parent or peer is the second step of the process. The third step is skill performance, in which there is an opportunity to perform the newly learned behavior in a structured, supportive, and responsive setting, such as a role-play (Gresham, 2002; Sheridan \& Walker, 1999). 
Coaching is another empirically supported strategy for improving social competence in children and adolescents (Gresham \& Nagle, 1980; Mize, 1995). Coaching procedures use direct verbal instruction as a means to teach social skills. The coaching procedure involves three steps: (a) presentation of rules or steps for the behavior, (b) an opportunity to practice, and (c) specific feedback regarding skill performance (Gresham, 2002).

Social problem solving (SPS) is a third strategy that has received support. SPS interventions target thoughts, emotions, and behaviors associated with social interactions. Frequently, aggressive youth demonstrate deficiencies in problemsolving skills (Goldstein et al., 1994). When a problem arises, social cues are interpreted incorrectly or responded to in an emotional, rather than intellectual manner (Elias \& Tobias, 1996). Several problem solving approaches aim to address these deficits by teaching children how to solve social problems though a series of steps including: (a) becoming aware of feelings, (b) recognizing problematic situations, (c) generating alternate solutions to problems, (d) evaluating consequences, (e) selecting a strategy, (f) engaging in the strategy, and (g) evaluating and modifying the strategy (Elias \& Tobias, 1996; Sheridan \& Walker, 1999).

Although such procedures have been shown to increase knowledge about appropriate social behaviors, the positive gains are short-term and behavioral generalization has not been demonstrated typically (Goldstein et al., 1994). Further, despite advances in problem solving thinking skills, little research has addressed the effect upon students' aggressive behaviors (Keller \& Tapasak, 1997).

Other-focused Strategies. In addition to interventions focusing on the child, there are several strategies that target other individuals, such as parents or peers. These interventions include parent training, peer-based interventions, and school-wide programs.

Parent training is a useful strategy for social skills training because parents are in many situations where they can observe and help their child improve social interactions. Parental involvement may take several forms. First, parents may be involved directly with social skill instruction. For example, they can participate in parent groups that provide important information regarding specific problematic and nonproblematic social situations (Sheridan, 1995; Sheridan, Dee, Morgan, McCormick, \& Walker, 1996). Second, parents can help set the stage for positive social interactions by providing opportunities for skill utilization as well as recognizing and discussing feelings surrounding their child's friendships (Sheridan, 1998). Finally, parents can provide supplemental training in natural settings via cueing, prompting, modeling and reinforcement of cooperative and pro-social behaviors (Sheridan et al., 1996).

Peer-based interventions present additional opportunities to increase prosocial behaviors. According to Gresham (2002), one type of peer-based strategy is peer-initiated contact. Peer initiated contact involves confederate peers who are used to begin and maintain interactions with a target child. Peers may be 
trained by teachers to approach a target child and initiate conversations or ask him or her to play. Peer-initiated contact appears to be especially effective for socially withdrawn children (Gresham, 2002).

Cooperative learning, another peer-based strategy, may prevent aggressive behavior in the classroom (Keller \& Tapasak, 1997). This approach involves a group of students working together on an academic task. Although each student in the group has a specific role, which promotes accountability, praise and reinforcement is based on group performance, thereby enhancing interdependence. Goals of cooperative learning strategies include improving peer relationships, classroom climate, inter-racial relationships and academic achievement (Slavin, 1990). To be effective in cooperative learning groups, a number of subskills are required, including: (a) getting started, (b) requesting assistance, (c) responding to requests, (d) providing assistance, and (e) verbalizing supportive statements (Cartledge \& Johnson, 1997).

Modeling and reinforcement of cooperative techniques is vital (Cartledge \& Johnson, 1997). CBC provides an opportunity for both home and school contexts to communicate congruent messages regarding the importance of cooperative, rather than competitive behaviors. Further, it increases the likelihood that modeling and systematic reinforcement of cooperative actions will occur across the respective settings (Sheridan \& Walker, 1999).

Ecological Strategies. Ecological interventions improve social competence by targeting the child's social environment. Examples of ecological strategies include the manipulation of antecedents and consequences, and school-wide interventions. Manipulation of antecedents, or events that precede desired social interactions, can create an environment that promotes pro-social behavior. In essence, it sets the stage for positive interactions. Examples of interventions thai manipulate antecedents include cueing, prompting the child to use learned prosocial behaviors, and peer-based strategies (Sheridan \& Walker, 1999).

Similarly, manipulation of consequences can effectively increase social competence by reinforcing pro-social behaviors. Contingent social reinforcement and differential reinforcement are two of the most commonly used procedures. Contingent social reinforcement is used typically for performance deficits and requires that the child possess requisite skills in his/her repertoire. The goal is for parents and/or teachers to provide praise or rewards when the child engages in socially appropriate behavior (Sheridan \& Walker, 1999).

Differential reinforcement procedures are used to decrease the frequency of undesired behaviors (Hansen, Nangle, \& Meyer, 1998; Sheridan \& Walker, 1999). It can be accomplished through differential reinforcement of other behaviors (DRO), differential reinforcement of low rates of behaviors (DRL), and differential reinforcement of incompatible behaviors (DRI). Differential reinforcement of other behaviors (DRO) provides reinforcement for any behavior except the target behavior. For example, a child who engages in teasing behavior on the 
playground may be reinforced for all instances of non-teasing behavior (e.g., playing alone, playing cooperatively with peers, keeping hands and feet to self). The effect is a reduction in the inappropriate target behavior as well as an increase in other prosocial behaviors (Gresham, 2002).

Differential reinforcement of low rates of behavior (DRL) delivers reinforcement for reduced rates of the target behavior. In the example above, a child who typically exhibits high levels of teasing behavior with peers may be reinforced for demonstrating lowered levels of the behavior. DRL procedures decrease the frequency of inappropriate social behaviors, however they rarely increase the frequency of positive behavior. Therefore, DRL strategies may be most helpful when paired with another strategy that teaches prosocial skills to replace the target behavior (Sheridan \& Walker, 1999).

Differential reinforcement of incompatible behaviors (DRI) refers to the delivery of reinforcement for behaviors that are incompatible with the target behavior. Unlike DRO and DRL strategies, which primarily attempt to decrease negative behaviors, DRI attempts to increase the frequency of prosocial behaviors. For example, a prosocial behavior that is incompatible with teasing (e.g., giving a compliment) might be reinforced (Gresham, 2002).

School-based programs can effectively prevent and reduce challenging behaviors. School-wide interventions include several components such as monitoring discipline procedures, stressing pro-social skill development, reducing the frequency of negative consequences, and emphasizing early school success (Lewis et al., 1998). School-based procedures are preventive in nature and therefore are implemented in large groups of students, only some of whom may be targeted as needing skill instruction. These approaches increase the likelihood that both the target child and his or her peers will obtain the knowledge and skills necessary to engage in pro-social interactions (Sheridan \& Walker, 1999). There are several commercial school-wide intervention/prevention programs available, such as "The Expect Respect Project," "Bully Busters," and the "Olweus Bullying Prevention Program." For comprehensive reviews of these programs, readers are referred to Whitaker et al. (see Chapter 16), Horne and Orpinas (see Chapter 15), and Limber (see Chapter 17).

\section{Treatment Implementation}

The third stage of the $\mathrm{CBC}$ process is treatment implementation. The primary objective of this stage is to implement the plan developed through the functional assessment across the home and school setting (Sheridan et al., 1996).

A central issue during treatment implementation is treatment integrity, which is defined as the degree to which an intervention is implemented as designed (Gresham, 1989). Adherence to established treatment components may affect intervention outcomes; therefore treatment integrity across home and school is important. School violence intervention integrity may be problematic for numerous 
reasons. Surveillance of larger areas such as school corridors and stairwells, extensive teaching loads and participation in specialized training may overburden intervention agents. Similarly, distractions and emergencies can sidetrack participants, thereby hindering treatment integrity (Goldstein, 1997).

Several procedures increase treatment integrity of school violence interventions. Procedures such as (a) providing a specific written plan containing intervention steps and responsibilities, (b) conducting direct observations of treatment implementation, (c) arranging times to meet or discuss plan components and modifications, and (d) encouraging consultees to self-monitor intervention implementation (Gresham, 1989) are all possible to effect integrity positively.

An additional consideration for the treatment implementation stage is data collection procedures. Data should continue to be gathered throughout the treatment phase and identical collection procedures are utilized to ensure comparability of baseline and treatment data. To enhance the reliability of data collection, procedures should be simple and easy to use. In addition, it is helpful to provide consultees with collection forms indicating the day and time data are to be gathered (Sheridan et al., 1996).

\section{Treatment Evaluation}

The fourth and final stage of $\mathrm{CBC}$ is treatment evaluation. There are two main goals of this stage: (a) evaluating treatment effectiveness, and (b) programming for generalization and maintenance (Sheridan \& Elliott, 1991; Sheridan et al., 1996).

\section{Evaluating Treatment Effectiveness}

Identical assessment methods used throughout the aforementioned stages of CBC (e.g., behavioral observations, parent and teacher ratings) are used to evaluate the effectiveness of the treatments implemented in CBC. The effectiveness of a social intervention is determined by several factors including the degree of behavior change, immediacy of change once treatment is implemented, and maintenance and generalization of behavior change once intervention strategies are no longer in place (Sheridan \& Elliott, 1991). Each of these indices of treatment effectiveness can be assessed from direct observational data over the course of treatment. Visual and statistical analyses (e.g., trend, stability, effect sizes) can be conducted to assess the change in the target behavior throughout baseline, treatment, and follow-up phases of the intervention, thereby providing a clear picture of treatment effectiveness.

Additional indices of treatment effectiveness include measures of social validity (Kazdin, 1977; Sheridan \& Walker, 1998). Parent and teacher perceptions of social-behavioral change is one outcome measure that accounts for the social validity or meaningfulness of the intervention and consequent behavior change within the child's social environments. Consultee perception data are gathered 
via direct interviews with the consultant and through rating scales that measure the child's social behavior. Parents and teachers can provide information regarding relationships with peers and perceptions of social status. Consultee reports of behavior change and improved social standing indicate that the treatment implemented in consultation was effective.

Peer comparison is another way to assess the meaningfulness of behavioral change. Observations of not only the target child, but his or her peers, can provide information regarding social behavior in comparison in a normative social context. Data indicating that the child's behavior approximates that of peers provides support for the social skills treatment procedures utilized in consultation.

\section{Programming for Generalization and Maintenance}

A second goal of treatment evaluation is concerned with assessing and planning for the generalization and maintenance of treatment effects. Effective social skills treatment programs are those that promote generalization across settings, time, and behaviors. In contrast to a "train and hope" philosophy (whereby social behaviors are taught in decontextualized conditions and are expected to generalize naturally to the criterion environment; Stokes \& Baer, 1977), active generalization programming is generally required to promote skill use in natural social settings. Some important generalization strategies that have been documented include: (a) teaching behaviors that are likely to be maintained by naturally occurring contingencies; (b) training across stimuli (e.g., persons and setting); (c) fading response contingencies to approximate naturally occurring consequences; (d) reinforcing application of skills to new and appropriate situations; and (e) including peers in training (Michelson, Sugai, Wood, \& Kazdin, 1983; Stokes \& Baer, 1977). A foundation for each of these strategies is the notion of developing training experiences that closely approximate the "real world" (Sheridan et al., 1999). It is possible that incorporating real world stimuli, contingencies, and experiences into training procedures will facilitate generalized use of social behaviors, although more research is needed to evaluate this assumption. Likewise, implementation of programs in naturalistic settings and contexts (such as cooperative learning, schoolwide interventions, in vivo conflict mediation, and structured recess programs) is expected to minimize the disconnect between training and criterion settings and thus facilitate generalized skill use.

Generalization between school and home settings is an additional concern in comprehensive social intervention programs, and such procedures are inherent within the CBC model. CBC facilitates generalization through involvement of individuals from both environments in the problem solving process, allowing for comprehensive information gathering, as well as consistent programming and reinforcement across both home and school. Similarly, parents and teachers are in an excellent position to monitor unplanned or undesired intervention effects (Sheridan et al., 1996). 


\section{TRANSLATING RESEARCH \\ INTO PRACTICE: IMPLICATIONS FOR BULLYING PREVENTION AND INTERVENTION PROGRAMS}

The advartages of using $\mathrm{CBC}$ to address concerns related to social competence and bullying in children and adolescents can be illustrated through a case study. The case highlights several key aspects of the process. First, it represents the importance of using a variety of assessment tools to obtain comprehensive data regarding a child's social skills and problems across several settings. Second, it illustrates the utility of linking information gained from assessment to plan development. Third, systematic evaluation of the case is demonstrated. Finally, the process was conducted in the child's natural setting to promote generalization and maintenance of social gains.

\section{Background Information}

Matthew was an 8-year-old, third grade male with average intellectual and language abilities who attended a Midwestern parochial school. He displayed an awkward social interaction style, which resulted in teasing and bullying from classmates. Matthew responded to the taunts by becoming physically aggressive with his peers, thereby extending the conflict. He also had a negative reputation with teachers due to his frequent altercations with peers. Matthew's mother initially referred her son to $\mathrm{CBC}$ for difficulty developing peer relationships and aggressive behavior. She indicated that he was socially withdrawn and tended to isolate himself from the group.

\section{Problem Identification}

Several assessment methods were utilized to gather information regarding Matthew's social interactions and to define the target behavior. Procedures used to assess microsystemic influences included standardized behavior rating scales (Parent and Teacher forms of the Social Skills Rating Scale [SSRS]; Gresham \& Elliott, 1990), self-report scales (SSRS-Self Report; Gresham \& Elliott, 1990) and direct observations across home and school settings. The combination of measures provided information on Matthew's social interactions, such as responses to bullying and aggressive behavior as well as reactions from others (peers, teachers, parents) across home and school settings.

A Conjoint Problem Identification Interview was conducted to establish a positive working relationship between Matthew's mother and teacher and to prioritize behavioral difficulties. During the meeting, his mother and teacher shared several concerns regarding Matthew's ability to read social cues appropriately. Specific target areas included knowing when another child was interested 
in the topic of conversation, how to end a conversation, responding to problem situations in a non-aggressive manner, and initiating positive social interactions with peers. Through problem exploration and dialogue, Matthew's mother, teacher, and the consultant determined that the most important behavior (i.e., priority) for the home and school settings was initiation of positive social interactions with peers.

Behavior checklists (SSRS-P, SSRS-T) indicated that Matthew demonstrated poor social initiation skills. Specific items that were rated as never or sometimes true by Matthew's mother and or teacher included "Invites others to join in," "Joins ongoing activity or group without being told to do so," "Introduces himself to new people without being told," and "Invites others to your home." The self-report checklist (SSRS) also demonstrated difficulty with peer interactions. Specific items rated as never or sometimes true by Matthew included "I start talks with class members" and "I make friends easily."

Consultees conducted direct observations of Matthew's social interactions with peers. Specifically, observations were made on Matthew's initiation of pro-social contact with classmates. Direct measures were also utilized. An independent observer conducted twenty-minute direct observations three times per week throughout the process to examine Matthew's social interactions across time and setting.

\section{Problem Analysis}

A Conjoint Problem Analysis Interview was conducted to review baseline data, conduct a functional assessment and develop a treatment plan. During the data collection period, direct observations indicated that Matthew initiated one social interaction per day. Observations conducted by Matthew's teacher revealed that Matthew initiated one social interaction in the school setting. Similarly, Matthew's mother reported that her son initiated two social interactions with neighbors each day. It was noted that Matthew was passive in social situations with peers (i.e., he tended to observe play from outside the peer group rather than participate actively). Observations and a review of conditions surrounding his passive behaviors suggested that he was lacking the necessary prerequisite skills to develop appropriate assertive behavior. Based on the data collected, the consultation goal was set at the initiation of two social interactions per day.

Because Matthew did not appear to have the necessary pro-social interaction skills within his repertoire, the team developed a treatment plan geared toward teaching appropriate initiation and maintenance of positive interactions with peers. The plan, implemented across home and school settings, consisted of two components: (a) a social skills training program for Matthew that included modeling, coaching and behavioral rehearsal; and (b) instruction for the parents and teacher to prompt consistent and appropriate social interactions.

The social skills program was presented to Matthew and three of his peers. Within the program, discrete skills were taught for initiating conversations and 
joining into ongoing group activities. The program facilitator modeled the sequence of behavior necessary to perform the social skill. Matthew was encouraged to practice the newly learned social skills by role-playing with his peers. The role-plays took place in a nearby classroom to ensure a structured and safe practice setting. Once Matthew demonstrated skill acquisition, he was provided with opportunities to practice in more natural settings, such as the classroom and on the playground. Skill acquisition occurred when Matthew successfully completed eight sub-steps comprising the initiation skill (see Appendix).

Prompting from Matthew's parents and teachers served as the second component of the program. To address mesosytemic issues, Matthew's family, teacher and the consultant identified socially appropriate initiation behaviors as well as appropriate responses to bullying or aggression from peers. It was important to ensure both home and school settings were providing consistent messages on how to initiate contact with peers and how to respond when peers engaged in bullying behavior. The program leader taught the parents and teacher specific in vivo cueing procedures that would facilitate pro-social interactions. Matthew's mother and teacher were encouraged to observe Matthew's social behaviors and approach him in situations when he could use an appropriate social skill, but failed to do so. They made a statement reminding Matthew of the specific social skill steps and suggested that he use those steps in the current situation. Examples of prompts included "Matthew, today at recess would be a good place to practice your skill of ..." In addition, Matthew's parents and teachers provided specific praise and feedback regarding Matthew's performance of the skill. Praise procedures were based on the IFEED acronym (i.e., praise was delivered Immediately, Frequently, with Enthusiasm, with Eye contact, and Descriptively; Rhode, Jenson, \& Reavis, 1992; Sheridan, 1998). An example of an effective praise statement is "Matthew, you did a great job starting a conversation with Sally!"

\section{Treatment Evaluation}

During the Treatment Evaluation stage, behavioral rating scales and direct observations were used to evaluate the effectiveness of the treatment plan. The SSRSParent Form, SSRS-Teacher Form, and SSRS-Self Report were re-administered following the treatment plan. Improvements were noted on parent, teacher and self-ratings of initiation of social interactions.

Observations from Matthew's mother and teacher revealed improvement in Matthew's social interactions with peers (see Fig. 13.1). Matthew's mother reported that her son improved his rate of initiating conversations to an average of five times per day. The teacher reported that Matthew increased his initiation of social interactions with peers to four times per day. Independent observations in the school setting were consistent with teacher observations. Evaluation of the plan indicated that the goal had been exceeded. Matthew's parents and teachers 


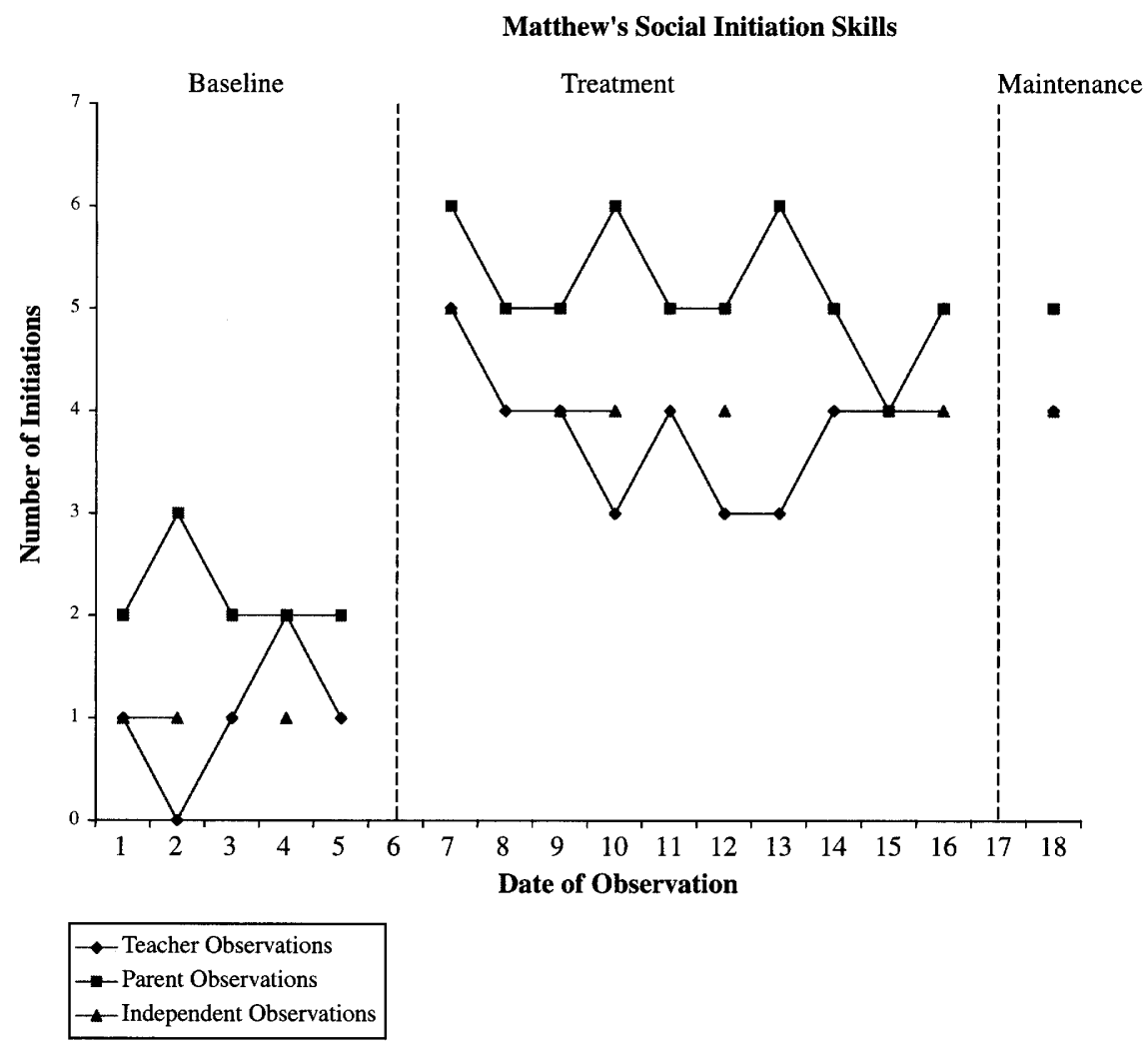

FIG. 13.1. Matthew's social-initiation behaviors across home and school settings.

continued to provide Matthew with opportunities to practice his skills in natural environments to promote generalization. Maintenance of treatment gains was facilitated by a gradual fading of specific praise on Matthew's performance. Specifically, Matthew's parents and teacher began to provide intermittent praise and feedback following a prosocial interaction with peers.

Despite improvement in Matthew's social interactions with peers, some challenges were encountered during implementation of the plan. Time involvement on behalf of the parents, teacher and consultant was a challenging aspect of the case. The consultation team met bimonthly for several months. Each meeting lasted approximately one hour. Although regularly scheduled meetings provided opportunities for ongoing communication and plan modifications, it required flexibility with schedules, numerous hours spent within the school building and high levels of investment on the part of the parents and teacher. Whereas these 
were deemed necessary and appropriate for Matthew's case, the nature of involvement may look different for each school and family.

\section{Summary}

Bullying and victimization among children and youth are common concerns of families and schools today. An ecological approach to address such issues encourages conceptualization of issues and interventions at multiple ecological levels, including the child in his/her immediate setting, adults within multiple environments, and importantly, relationships among those environments. The focus of this chapter was interventions at the mesosytemic level through the development of meaningful and supportive partnerships between home and school contexts. Conjoint behavioral consultation (CBC) is one method by which homes and schools can work together to promote healthy social development of children and youth. Through this model of consultation, a range of ecologically relevant variables that effect children's social functioning in home and school are explored. Such analyses provide relevant contextual information that contributes to the design, implementation, and evaluation of effective interventions at the child, adult, or system level. Continued collaboration among home and school systems is essential and can be promoted by involving parents and teachers in a joint problem-solving process, allowing for comprehensive and on-going attention to address bullying and victimization concerns for children.

\section{REFERENCES}

Baker, D. P., \& Stevenson, D. L. (1986). Mothers' strategies for children's school achievement: Managing the transition to high school. Sociology of Education, 59, 156-166.

Becher, R. M. (1984). Parent involvement: A review of research and principles for successful practice. Urbana, IL: ERIC Clearinghouse on Elementary and Early Childhood Education. (ERIC Document Reproduction Service No. ED 247-032).

Bloom, B. S. (1985). Developing talents in young people. New York: Ballantine Books.

Bracken, B. A. (1993). Assessment of interpersonal relations. Austin, TX: Pro-Ed.

Bronfenbrenner, U. (1979). The ecology of human development. Cambridge, MA.: Harvard University Press.

Cartledge, G., \& Johnson, C. T. (1997). School violence and cultural sensitivity. In A. P. Goldstein, \& J. Conoley (Eds.), School violence intervention: A practical handbook (pp. 391-425). New York: Guilford Press.

Christenson, S. L. (1995). Supporting home-school collaboration. In A. Thomas \& J. Grimes (Eds.), Best practices in school psychology III (pp. 253-267). Washington, DC: National Association of School Psychologists.

Christenson, S. L., \& Sheridan, S. M. (2001). Schools and families: Creating essential connections for learning. New York: Guilford Press.

Clark, R. M. (1988). Parents as providers of linguistic and social capital: How do the literacy skills of low achievers and high achievers differ, and how do parents influence these differences? Educational Horizons, 66(2), 93-95. 
Clark, R. M. (1993). Homework-focused parenting practices that positively affect student achievement. In N. F. Chavkin (Ed.), Families and schools in a pluralistic society (pp. 85-105). Albany: State University of New York Press.

Collins, C. H., Moles, O., \& Cross, M. (1982). The home-school connections: Selected partnership programs in large cities. Boston, MA: Institute for Responsive Education.

Comer, J. P. (1988). Educating poor minority children. Scientific American, 259(5), 2-8.

Comer, J. P., \& Haynes, N. M. (1991). Parent involvement in schools: An ecological approach. Elementary School Journal, 91(3), 271-278.

Conoley, J. C. (1987). Schools and families: Theoretical and practical bridges. Professional School Psychology, 2, 191-203.

Crick, N. R., \& Dodge, K. A. (1994). A review and reformulation of social information-processing mechanisms in children's social adjustment. Psychological Bulletin, 115, 74-101.

Davies, D. (1993). Benefits and barriers to parent involvement: From Portugal to Boston to Liverpool. In N. F. Chavkin (Ed.), Families and schools in a pluralistic society (pp. 53-72). Albany: State University of New York Press.

Eagle, E. (1989, April). Socioeconomic status, family structure, and parental involvement: The correlates of achievement. Paper presented at the annual meeting of the American Educational Research Association, San Francisco. (ERIC Document Reproduction Service No. ED $307332)$

Elias, M. J., \& Tobias, S. E. (1996). Social problem solving: Interventions in the schools. New York: Guildford Press.

Elliott, S. N., \& Busse, R. T. (1991). Social skills assessment and intervention with children and adolescents: Guidelines for assessment and training procedures. School Psychology International, $12,63-83$.

Epstein, J. L. (1986). Parents' reactions to teacher practices of parent involvement. Elementary School Journal, 86, 277-294.

Epstein, J. L. (1991). Effects on student achievement of teachers' practices of involvement. In B. S. Silvern (Ed.), Advances in reading/language research: Vol. 5. Literacy through family, community, and school interaction (pp. 261-276). Greenwich, CT: JAI Press.

Epstein, J. L. (1995). School/family/community partnerships: Caring for the children we share. Phi Delta Kappan, 76, 701-712.

Epstein, J. L., \& Becker, H. J. (1982). Teacher practices of parent involvement. The Elementary School Journal, 83, 103-113.

Estrada, P., Arsenio, W. F., Hess, R. D., \& Holloway, S. (1987). Affective quality of the mother-child relationship: Longitudinal consequences for children's school-relevant, cognitive-functioning. $D e-$ velopmental Psychology, 23, 210-215.

Fehrmann, P. G., Keith, T. Z., \& Reimers, T. M. (1987). Home influences on school learning: Direct and indirect effects of parent involvement on high school grades. Journal of Educational Research, 80, 330-337.

Goldstein, A. P. (1997). Controlling vandalism: The person-environment duet. In A. P. Goldstein \& J. C. Conoley (Eds.), School violence intervention: A practical handbook (pp. 290-321). New York: Guilford Press.

Goldstein, A. P., Harootunian, B., \& Conoley J. C. (1994). Student aggression: Prevention, management, and replacement training. New York: Guilford Press.

Gresham, F. M. (1989). Assessment of treatment integrity in school consultation and prereferral intervention. School Psychology Review, 18, 37-50.

Gresham, F. M. (2002). Best practices in social skills training. In A. Thomas \& J. Grimes (Eds.), Best practices in school psychology - IV (pp. 1029-1040). Washington D.C.: National Association of School Psychologists.

Gresham, F. M., \& Elliott, S. N. (1990). Social Skills Rating System: Manual. Circle Pines, MN: American Guidance Services. 
Gresham, F. M., \& Nagle, R. J. (1980). Social skills trained with children: Responsiveness to modeling and coaching as a function of peer orientation. Journal of Consulting and Clinical Psychology, 48, 718-729.

Hansen, D. A. (1986). Family-school articulations: The effects of interaction rule mismatch. American Educational Research Journal, 23, 643-659.

Hansen, D. J., Nangle, D. W., \& Meyer, K. A. (1998). Enhancing the effectiveness of social skills interventions with adolescents. Education and Treatment of Children, 21, 489-513.

Haring, T. G. (1992). The context of social competence: Relations, relationships, and generalization. In S. L. Odom, S. R. McConnell, \& M. A. McEvoy (Eds.), Social competence of young children with disabilities: Issues and strategies for intervention (pp. 307-320). Baltimore, MD: Brookes.

Hoier, T. S., \& Cone, J. D. (1987). Target selection of social skills for children: The templatematching procedure. Behavior Modification, 11, 137-163.

Hoier, T. S., McConnell, S., \& Pallay, A. G. (1987). Observational assessment for planning and evaluating educational transitions: An initial analysis of template matching. Behavioral Assessment, 9, 5-19.

Hops, H., Walker, H. M., \& Greenwood, C. R. (1988). Procedures for establishing effective relationship skills (PEERS): Manual for consultants. Delray, FL: Educational Achievement Systems.

Kagan, S. L. \& Schraft, C. M. (1982). When parents and schools come together: Differential outcomes of parent involvement in urban schools. Boston, MA: Institute for Responsive Education. (ERIC Document Reproduction Service N. ED 281-951)

Kazdin, A. E. (1977). Assessing the clinical or applied importance of behavior change through social validation. Behavior Modification, 1, 427-452.

Kellaghan, T., Sloane, K., Alvarez, B., \& Bloom, B. S. (1993). The home environment and school learning: Promoting parental involvement in the education of children. San Francisco: Jossey-Bass.

Keller, H. R., \& Tapasak, R. C. (1997). Classroom management. In A. P. Goldstein, \& J. C. Conoley (Eds.), School violence intervention: A practical handbook (pp. 107-126). New York: Guilford Press.

Kratochwill, T. R., \& Stoiber, K. C. (2002). Evidence-based interventions in school psychology: Conceptual foundations of the procedural and coding manual of Division 16 and the Society for the Study of School Psychology task force. School Psychology Quarterly, 17, 341-389.

Lazar, L., \& Darlington, R. B. (1978). Summary: Lasting effects after preschool. Ithaca, NY: Cornell University Consortium for Longitudinal Studies. (ERIC Document Reproduction Service No. Ed 175-523)

Lewis, T. J., Sugai, G., \& Colvin, G. (1998). Reducing problem behavior through school-wide system of effective behavioral support: Investigation of a school-wide social skills training program and contextual interventions. School Psychology Review, 27, 446-459.

Marjoribanks, K. (1988). Perceptions of family environments, educational and occupational outcomes: Social-status differences. Perceptual and Motor Skills, 66, 3-9.

Merrell, K. W., \& Gimpel, G. A. (1998). Social skills of children and adolescents: Conceptualization, assessment, treatment. Mahwah, NJ: Lawrence Erlbaum Associates.

Michelson, L., Sugai, D. P., Wood, R. P., \& Kazdin, A. E. (1983). Social skills assessment and training with children: An empirically based approach. New York: Plenum.

Mize, J. (1995). Coaching preschool children in social skills: A cognitive-social learning curriculum. In G. Cartledge \& J. F. Milburn (Eds.), Teaching social skills to children and youth: Innovative approaches (3rd ed., pp. 237-261). Boston: Allyn \& Bacon.

Pianta, R., \& Walsh, D. (1996). High risk children in schools: Constructing sustaining relationships. New York: Routledge.

Resnick, M. D., Bearman, P. S., Blum, R. W., Bauman, K. E., Harris, K. M., Jones, J., Tabor, J., Beuhring, T., Sieving, R. E., Shew, M., Ireland, M., Bearinger, L. H., \& Udry, J. (1997). Protecting adolescents from harm: Findings from the National Longitudinal Study on adolescent health. The Journal of the American Medical Association, 278, 823-832. 
Rhode, G., Jenson, W. R., \& Reavis, H. K. (1992). The tough kid book. Longmont, CO: Sopris West.

Rumberger, R. W. (1995). Dropping out of middle school: A multilevel analysis of students and schools. American Educational Research Journal, 32, 583-625.

Sattes, B. (1985). Parent involvement: A review of the literature (Report No. 21). Charleston, WV: Appalachia Educational Laboratory.

Sheridan, S. M (1995). The tough kid social skills book. Longmont, CO: Sopris West.

Sheridan, S. M. (1998). Why don't they like me? Helping your child make and keep friends. Longmont, CO: Sopris West.

Sheridan, S. M., Dee, C. C., Morgan, J. C., McCormick, M. E., \& Walker, D. (1996). A multimethod intervention for social skills deficits in children with ADHD and their parents. School Psychology Review, 25, 57-76.

Sheridan, S. M., \& Elliott, S. N. (1991). Behavioral consultation as a process for linking the assessment and treatment of social skills. Journal of Educational and Psychological Consultation, 2, 151-173.

Sheridan, S. M., Hungelmann, A., \& Maughan, D. (1999). A contextualized framework for social skills assessment, intervention, and generalization. School Psychology Review, 28, 84-103.

Sheridan, S. M., Kratochwill, T. R., \& Bergan, J. R. (1996). Conjoint behavioral consultation: A procedural manual. New York: Plenum Press.

Sheridan, S. M., \& Walker, D. (1999). Social skills in context: Considerations for assessment, intervention, and generalization. In C. R. Reynolds \& T. B. Gutkin (Eds.), The handbook of school psychology (3rd ed., pp. 686-708). New York: Wiley \& Sons.

Slavin, R. E. (1990). Research on cooperative learning: Consensus and controversy. Educational Leadership, 47, 52-54.

Steinberg, L., Mounts, N. S., Lamborn, S. D., \& Dornbusch, S. M. (1991). Authoritative parenting and adolescent adjustment across varied ecological niches. Journal of Research on Adolescence, l(1), 19-36.

Stevenson, D., \& Baker, D. (1987). The family-school relation and the child's school performance. Child Development, 58, 1348-1357.

Stokes, T., \& Baer, D. (1977). An implicit technology of generalization. Journal of Applied Behavior Analysis, 19, 349-367.

Walker, H., \& McConnell, S. (1988). Walker-McConnell Scale of Social Competence. Austin, TX: Pro-Ed.

Witt, J. C., Martens, B. K., \& Elliott, S. N. (1984). Factors affecting teachers' judgments of the acceptability of behavioral interventions: Time involvement, behavior problem severity, and type of intervention. Behavior Therapy, 15, 204-209. 


\section{APPENDIX: STEPS OF SOCIAL ENTRY}

1. Faces the other person (i.e., body is square to the other when appropriate, or head turns toward other when in conversation). To receive credit, this behavior must occur for the majority of the interaction.

2. Uses eye contact (i.e., eyes look into face of other in a comfortable and appropriate manner, rather than on floor, out window, or staring inappropriately). To receive credit, this behavior must occur for the majority of the interaction.

3. Maintains appropriate physical space (i.e., approximately two arms lengths away when in conversation, or appropriately closer or further when the situation calls for it such as when whispering or playing a team sport). To receive credit, this behavior must occur for the majority of the interactions.

4. Maintains a neutral body posture (i.e., hands, arms and legs appear loose and relaxed, fists are not clenched). To receive credit, this behavior must occur for the majority of the interaction.

5. Uses an appropriate voice (i.e., voice is audible to those in immediate proximity but not to persons at a distance of 10 feet or more unless situation calls for it, inflection in voice is appropriate to the conversation rather than sarcastic or snide). To receive credit, this behavior must occur for the majority of the interaction.

6. Waits for a good time (i.e., does not interrupt on-going conversation or activity such that behavior evokes negative reaction from others; allows no more than 5-7 seconds to elapse before making a clear verbal initiation).

7. Makes opening statement (i.e., uses appropriate voice tone and emotional tone and appropriate greeting to initiate interaction such as "Hello!," "Hi!," "How are you doing?," states the other child's name).

8. Appropriately initiates interaction or asks to join (i.e., uses appropriate voice and emotional tone, and spontaneously makes a statement or gesture clearly requesting another to engage in a mutual activity or conversation).

Total 